\title{
INOVAÇÃO ORGANIZACIONAL DA INDÚSTRIA DE PETRÓLEO, GÁS NATURAL E BIOCOMBUSTÍVEIS - A GESTÃO DO CONHECIMENTO
}

\author{
Classificação JEL: D83 Search - Learning - Information and Knowledge • \\ Communication • Belief • Unawareness
}

Jacks Williams Peixoto Bezerra - jacksbezerra@gmail.com

Universidade Federal do Rio de Janeiro - Instituto de Psicologia (Mestrando)

\section{Resumo}

Ao Setor de Petróleo e Gás do Brasil destina-se mais de $\mathrm{R} \$ 50$ bilhões por ano em investimentos. A cadeia de valor do petróleo representa 12\% do Produto Interno Bruto. No País, até 2020, R \$950 bilhões serão aportados nesta cadeia de bens e serviços como investimentos e gastos diretos. A competitividade internacional no Setor exige que o Brasil enfrente complexos desafios tecnológicos e de mercado. A Inovação é fundamental para a estratégia competitiva, pois permite ampliar mercados e reduzir custos. A inserção da gestão do conhecimento, contexto de novas técnicas de gestão, é inovação organizacional. Na Conclusão afirma-se ser necessário investigar o modelo de gestão do conhecimento e inovação da Petrobras para se apreender o sistema, bem como pesquisar como sistemas computacionais conectados a macroprocessos finalísticos e a objetivos estratégicos agregam valor às capacitações e capacidades da Petrobras. Também destaca ser significativo saber como as ações Programa Mentor Petrobras, Rodízio Técnico e Lições Aprendidas respondem aos desafios de conhecimento e inovação da Empresa, além de se reconhecer como o CENPES responde às necessidades de inovação organizacional e como esta transborda para o Sistema.

Palavras chaves: gestão de pessoas; gestão do conhecimento; inovação; inovação organizacional; petróleo e gás natural.

\begin{abstract}
The Oil \& Gas Brazil meant more than R \$ 50 billion a year in investments. The oil value chain represents $12 \%$ of gross domestic product. In the country by $2020, \mathrm{R} \$ 950$ billion will be invested in this chain of goods and services such as direct investment and spending. International competitiveness in the sector requires that Brazil faces complex technological and market challenges. Innovation is key to competitive strategy, as it allows expand markets and reduce costs. The integration of knowledge management, context of new management techniques, is organizational innovation. In conclusion it is stated to be necessary to investigate the management model Petrobras' knowledge and innovation to grasp the system as well as researching how computer systems connected to finalistic macro processes and strategic objectives add value to the skills and capabilities of Petrobras. It also highlights be significant to know how the Mentor Program Petrobras shares Caster Technical and Lessons Learned respond to the challenges of knowledge and innovation company, and be recognized as the CENPES responds to organizational innovation needs and how it spills over into the System.
\end{abstract}

Key words: people management; knowledge management; innovation; organizational innovation; oil and natural gas. 


\section{Introdução}

A Indústria de Exploração e Produção (E\&P) de Petróleo e Gás, no Brasil, é detentora de cenário de investimento cujos valores ultrapassam R\$ 77 bilhões/ano. Neste contexto, a cadeia de valor do petróleo aponta para a marca de $12 \%$ do Produto Interno Bruto. Deste modo, quanto ao Negócio Petróleo, a descontinuidade de atividades exploratórias passaria a provocar desmobilização de equipes de alto nível técnico, em especial de empresas de menor porte ou de subsidiárias de companhias internacionais com pequenas carteiras de projetos em Exploração e Produção. Em vista disto, a mobilização de novos profissionais na retomada de atividades levaria considerável tempo - com elevados custos para as companhias. Deste modo, há urgência de que se decida por Leilões vinculados a novos blocos exploratórios em águas profundas. Isto favoreceria o planejamento estratégico empresarial e a melhor condição para que o risco de interrupção em Investimentos fosse bem minimizado. Por decorrência, a maior sustentabilidade dos Negócios seria protegida e potencializada. Vale destacar que há a previsão de que, até o ano de 2020, patamares de R\$ 950 bilhões sejam destinados, ao País, mediante investimentos e gastos diretos - cadeia de bens e serviços em Óleo \& Gás. Por fim, chama a atenção a informação de que na última década houve significativo crescimento no nível de investimentos nesta Indústria, o que provocou aumento de demanda da Cadeia em cinco vezes, mas sem que houvesse o acompanhamento, mesmo com o crescimento da oferta local, de novas demandas por produtos, serviços e mão de obra. (IBP, [201-], p. 17-19)

Deste modo, ALMEIDA (2016) destaca que a competitividade em Petróleo e Gás, do/no Brasil, na sua dinâmica cotidiana de mercado, precisa lidar com os desafios e estratégias de redução de custos na Exploração e Produção Offshore. Tal condição diz respeito, inclusive, às soluções tecnológicas específicas para a complexidade de cada projeto, à tendência de se privilegiar soluções de maior conteúdo tecnológico não necessariamente mais rentáveis e ao elevado grau de divisão do trabalho e de terceirização - em um cenário de alta quantidade de empresas envolvidas nas Operações. Estes Desafios tornam-se ainda mais significativos no atual cenário de alta queda de preços do petróleo, no mercado internacional, e de estratégias assumidas de grandes players empresariais e de governo deste Mercado - por exemplo: os não convencionais nos Estados Unidos e a exploração de areia betuminosa no Canadá.

TIGRE (2014, p. 201), por sua vez, alerta que na indústria petroquímica do Brasil os técnicos estão capacitados para compreender e aperfeiçoar processos industriais, todavia carecem de habilidades para aproveitarem o melhor que o potencial humano existente pode oferecer. Assim, é possível que não só as habilidades se apresentem limitadas, mas sim um mais amplo leque de competências comportamentais - condição que pode impactar, de forma negativa, capacitações e inovações organizacionais do Setor.

Em paralelo à dinâmica do mercado de Óleo \& Gás, o Brasil desenvolve a Pesquisa de Inovação PINTEC. Esta é uma pesquisa-satélite de corte transversal do Sistema de Estatísticas Econômicas e que agencia Indicadores abrangentes e com comparabilidade internacional - em termos conceituais e metodológicos. Esta Pesquisa é realizada pelo Instituto Brasileiro de Geografia e Estatística (IBGE) e há o apoio da Financiadora de Estudos e Projetos (FINEP) e do Ministério da Ciência, Tecnologia e Inovação (MCTI).

Nesse cenário de Pesquisas PINTEC, este Artigo agencia as Pesquisas de Inovação Tecnológica 2008 e Pesquisa de Inovação 2011. Esta delimitação decorre do fato de que 
a partir da Pintec 2008 a Inovação passou a ser analisada por um conceito mais amplo não somente inovação tecnológica de produto e processo. Incorporou, assim, as inovações não tecnológicas. Em vista disto, há o destaque para se levar em conta que a implementação de novidades organizacionais pode melhorar o uso do conhecimento, além da eficiência de fluxos de trabalho, ou seja, da própria qualidade e efetividade dos bens e serviços de empresas. Vale assinalar que mediante a PINTEC 2008 também tem início a pesquisa sobre inovações de marketing. (IBGE, 2010, p. 57)

Em vista disto, a PINTEC informa que a Inovação Organizacional - que não inclui fusões e aquisições, mesmo sendo a primeira vez,

... compreende a implementação de novas técnicas de gestão ou de significativas mudanças na organização do trabalho e nas relações externas da empresa, com vistas a melhorar o uso do conhecimento, a eficiência dos fluxos de trabalho ou a qualidade dos bens ou serviços. Deve ser resultado de decisões estratégicas tomadas pela direção e constituir novidade organizativa para a empresa. (IBGE, 2010, p. 156)

Assim, a PINTEC compromete-se a identificar de forma objetiva se houve:

- 188 Novas técnicas de gestão para melhorar rotinas e práticas de trabalho, assim como o uso e a troca de informações, de conhecimento e habilidades dentro da empresa. Por exemplo: re-engenharia dos processos de negócio, gestão do conhecimento, controle da qualidade total, sistemas de formação/treinamento, SIG (sistemas de informações gerenciais), ERP (planejamento dos recursos do negócio) etc.

- 189 Novas técnicas de gestão ambiental para tratamento de efluentes, redução de resíduos, de $\mathrm{CO}_{2}$ etc.

- 190 Novos métodos de organização do trabalho para melhor distribuir responsabilidades e poder de decisão, como por exemplo o estabelecimento do trabalho em equipe, a descentralização ou integração de departamentos etc.

- 190.1 Mudanças significativas nas relações com outras empresas ou instituições públicas e sem fins lucrativos, tais como o estabelecimento pela primeira vez de alianças, parcerias, terceirização ou sub-contratação de atividades. (IBGE, 2010, p. 156)

Assim, este Artigo, norteado por conceitos das PINTEC/IBGE 2008 e 2011, incluindo referenciais do Manual de Oslo (OCDE, 1997), agencia reflexão crítica sobre Inovação Organizacional - Novas Técnicas de Gestão no contexto da Gestão do Conhecimento - nas Áreas de fabricação de coque, de produtos derivados do petróleo e de biocombustíveis; de fabricação de coque e biocombustíveis (álcool e outros); de refino de petróleo. Isto se deve pelo fato de alta competitividade e relevância que este Setor e o Conhecimento têm para a nossa Economia e para a própria sustentabilidade empresarial e social.

\section{Objetivo}


O objetivo do Artigo é o de problematizar a interface e a relevância estratégica que há entre inovação organizacional (novas técnicas de gestão/gestão do conhecimento) e a sustentabilidade empresarial da Indústria do Petróleo, Gás Natural e Biocombustíveis do Brasil. Microcenário da cadeia produtiva do Setor, o da Petrobras, permite a pesquisa investigativa. Informações (conceitos e dados) do Manual de Oslo e da Série PINTEC 2008 e 2011 - no cenário da fabricação de coque, de produtos derivados do petróleo e de biocombustíveis; da fabricação de coque e biocombustíveis (álcool e outros); do refino de petróleo - oferecem suporte analítico à reflexão crítica.

\section{Metodologia}

O Método de Procedimento adotado para a coleta de dados e informações e para a Análise vincula-se ao Método Monográfico (Prodanov e Freitas, 2013, p. 39), o qual tem como princípio norteador que o estudo de um caso pode ser representativo de outros ou de todos os casos semelhantes. Deste modo, o estudo de caso diz respeito a indivíduos, a grupos, a comunidades e a instituições. O Estudo de Caso deste Estudo refere-se à Inovação Organizacional quanto à Gestão do Conhecimento da Petrobras cujos dados e informações são de domínio público quando disponibilizados em relatórios institucionais e em demais plataformas eletrônicas abertas da Empresa. Em vista disto, neste escopo promoveu-se levantamentos bibliográficos, documentais e estatísticos, além do Estudo de Caso selecionado. A Conclusão apresenta proposta de desdobramento de pesquisa, além de encerrar a presente análise crítica.

O Artigo está dividido em onze Seções - incluindo a Introdução e a Conclusão. A segunda Seção apresenta o Objetivo e a terceira a Metodologia. A quarta destaca aspectos de inovação e competitividade e se detém no Manual de Oslo. A quinta se pauta na PINTEC Pesquisa de Inovação Tecnológica 2008 e a sexta na PINTEC Pesquisa de Inovação 2011. A sétima integra Reflexão acerca das 2 Pesquisas PINTEC. A oitava agencia o cenário político e econômico da Indústria internacional de petróleo, gás natural e biocombustíveis e o Brasil neste contexto. A nona pontua a gestão organizacional e a gestão do conhecimento. A décima apresenta informações sobre a Gestão do Conhecimento da Petrobras.

Em vista disto, para a primeira e a oitava Seções do Artigo, subsídios acerca da Indústria de petróleo e gás natural foram levantados na página eletrônica do Grupo de Economia da Energia da Universidade Federal do Rio de Janeiro - no seu Boletim Infopetro. Este cenário se completa por informações constantes do portal eletrônico do Instituto Brasileiro de Petróleo, Gás e Biocombustíveis - IBP. Para a quarta Seção, a tradução do Manual de Oslo foi acessada no endereço eletrônico da Financiadora de Estudos e Projetos - FINEP. Para a primeira, quinta e sexta Seções, informações acerca das Pesquisas PINTEC Inovação Tecnológica 2008 e Pesquisa de Inovação 2011 foram coletas do sítio eletrônico do Instituto Brasileiro de Geografia e Estatística - IBGE. Para a décima Seção, o cenário Petrobras foi identificado mediante a sua própria divulgação corporativa: páginas da internet. Completa este arcabouço teórico e conceitual a pesquisa em fontes bibliográficas.

\section{A Inovação, a Competitividade e o Manual de OSLO}


SICSÚ (2015, p. 2-3) pontua ser importante garantir a maior apropriação de êxitos dos avanços científicos e tecnológicos que possibilitem Inovação. O foco é expandir investimentos para condições melhores de desenvolvimento. Ao destacar Schumpeter (1982), assinala o empresário inovador que apresenta produtos, sobremaneira inovações tecnológicas, com o propósito de lucros extraordinários. Este agente, mediante combinações, inova quanto a bens, métodos de produção e transporte. Cria mercados e novas formas de organizar a produção, além de inovar quanto a fontes de matéria-prima.

Em vista disto, o empresário inovador corre riscos e agencia a destruição criativa Schumpeter (1984) indicado por Sicsú (2015, p. 5). Deste modo, para o sistema evoluir se faz necessário sucatear processos de produção ao longo do tempo para que sejam abertos espaços para novos hábitos de consumo. Esta dinâmica diz respeito ao impulso fundamental que dá início e mantém a engrenagem do Capitalismo - a busca pelo novo. Variáveis como cultura inovadora, perfil inovador da classe empresarial e mecanismos de financiamento e crédito, dentre outros aspectos, são fundamentais para inserção e constância deste processo inovador, digo, a Inovação.

Neste contexto, o processo de inovação na organização, a partir de Tidd e Bessant (2015, p. 55), contempla quatro dimensões: a busca - análise do cenário interno e externo de ameaças e oportunidades de mudança. A seleção - decisão estratégica acerca de qual dos sinais identificados, na análise dos cenários, será trabalhado. A implementação - potencial da ideia inicial assumir algo novo, que será lançado no mercado interno ou externo (mas demanda conhecimentos), mediante realização de projetos sob condições de imprevisibilidade e pela capacidade de resolução de problemas. A captura de valor - pela inovação agencia-se as dimensões de adoção sustentável e de difusão, bem como de aprendizado vinculado à progressão de longo ciclo e voltado para o contínuo aperfeiçoamento.

Deste modo, por ser a Inovação a principal opção de estratégica para potencializar a competitividade de empresas, Pelegrin e Antunes Júnior (2015, p. 17) ressaltam que é a partir da Inovação que a firma consegue se inserir em mercados novos, ou seja, introdução de produto ou serviço novo, ampliação geográfica de produtos já existentes e a combinação de novos serviços e/ou produtos por espaços geográficos novos. Destacam (Ibid, p. 21) o conceito de ganhos relacionais, o qual faz referência àqueles resultados que a organização não consegue alcançar de forma individual. Isto significa que a empresa somente conquista os ganhos por meio de relacionamentos qualificados com demais atores ou parceiros - acesso a recursos externos.

Assim, relevante é destacar o quesito competitividade. O Manual de Oslo (OCDE, 1997, p. 43) pontua que inovações visam o desempenho da firma e que mudanças são feitas por pressupostos de que a Inovação: associa-se a incertezas quanto a resultados; integra investimento de ativos fixos e/ou intangíveis; é o substrato de transbordamentos para o Mercado; demanda utilização de conhecimento novo ou mesmo de novo uso ou combinação do conhecimento que existe; visa ganhar vantagem competitiva ou manter a competitividade - desempenho de mercado: mudança da curva de demanda de seus produtos ou serviços (expansão de mercados e consumidores) ou de sua curva de custos (redução). Inclui a necessidade de aprimorar a capacidade de inovação (maior capacidade de desenvolver produtos, processos e/ou conhecimentos novos).

Neste contexto, o Manual de OSLO, desenvolvido pela Organização para a Cooperação e Desenvolvimento Econômico - OCDE e pela Autoridade Estatística da 
União Europeia - Eurostat, constitui parte de família de manuais circunscrita à mensuração e interpretação de dados de ciência, tecnologia e inovação. O Material engloba manuais, diretrizes e guias sobre: pesquisa e desenvolvimento (Manual Frascati); sociedade da informação; indicadores de globalização; patentes; estatísticas de biotecnologia; recursos humanos em ciência e tecnologia (Manual Canberra). (OCDE, 1997, p. 12)

As políticas de suporte apropriado às inovações, para que sejam desenvolvidas de forma efetiva, necessitam inclusive de melhor entendimento acerca de vários aspectos que são críticos para o processo inovador. Destaca-se, então, atividades de inovação não incluídas na P\&D (Pesquisa e Desenvolvimento), bem como as interações entre atores, além dos fluxos relevantes de conhecimento - não se esquecendo da relevância de melhores informações. (OCDE, 1997, p. 15)

Deste modo, o Manual de Oslo (OCDE, 1997, p. 25), que visa a coleta de dados acerca de inovação no âmbito da firma, esclarece que a Inovação inclui várias atividades que não se inserem em Pesquisa e Desenvolvimento, tais como: últimas fases do desenvolvimento para pré-produção, produção e distribuição (incluindo atividades de desenvolvimento com menor grau de novidade); atividades de desenvolvimento e implementação para inovações como métodos novos tanto de marketing quanto organizacionais, que não são inovações nem de produto e nem de processo, e as atividades de suporte como treinamento e preparação para o mercado. Neste contexto, atividades de inovação também podem incluir a aquisição de conhecimentos externos, bem como bens de capital que não são parte da Pesquisa e Desenvolvimento.

Deste modo, há o seguinte conceito:

Uma inovação é a implementação de um produto (bem ou serviço) novo ou significativamente melhorado, ou um processo, ou um novo método de marketing, ou um novo método organizacional nas práticas de negócios, na organização do local de trabalho ou nas relações externas. (OCDE, 1997, p. 55)

Neste sentido, a inovação organizacional é conceituada como “a implementação de um novo método organizacional nas práticas de negócios da empresa, na organização do seu local de trabalho ou em suas relações externas”. Assim, esta Inovação pode visar o aperfeiçoamento de uma empresa a partir da redução de custos administrativos ou de transação. Estimula, ainda, a satisfação no local de trabalho - com potencial impacto na produtividade -, o ganho no acesso a ativos não transacionais (tal como o conhecimento externo não codificado) ou a redução de custos de suprimentos. (OCDE, 1997, p. 61-62)

Em vista disto, as inovações organizacionais pertinentes à Prática de Negócio dizem respeito à implementação de métodos novos para a organização tanto de rotinas quanto de procedimentos vinculados à condução do trabalho. Deste modo, isto inclusive inclui a implementação de práticas novas que visem melhorar o compartilhamento do aprendizado, bem como do conhecimento no interior da empresa. Neste contexto, por exemplo, temos o estabelecimento de bancos de dados com Melhores Práticas e Lições de modo que o Conhecimento se torne mais acessível a empregados, trabalhadores e/ou parceiros. (OCDE, 1997, p. 61-62)

\section{PINTEC - Pesquisa de Inovação Tecnológica 2008}




\begin{tabular}{|c|c|c|c|c|c|c|c|c|}
\hline \multicolumn{9}{|c|}{ IBGE Pesquisa de Inovação Tecnológica 2008} \\
\hline \multicolumn{9}{|c|}{$\begin{array}{l}\text { Tabela 1.1.24 - Empresas, total e as que não implementaram produto ou processo e sem projetos, com indicação das } \\
\text { inovações organizacionais e de marketing implementadas, segundo as atividades selecionadas da indústria e dos } \\
\text { serviços - Brasil - período } 2006-2008 \text {. }\end{array}$} \\
\hline \multirow{4}{*}{$\begin{array}{l}\text { Atividades } \\
\text { selecionadas da } \\
\text { Indústria e dos } \\
\text { serviços. }\end{array}$} & \multicolumn{8}{|c|}{ Empresas } \\
\hline & \multirow[t]{3}{*}{ Total } & \multicolumn{7}{|c|}{ Que não implementaram produto ou processo e sem projetos } \\
\hline & & \multicolumn{5}{|c|}{ Inovações organizacionais } & \multicolumn{2}{|c|}{ Inovações de marketing } \\
\hline & & & $\begin{array}{l}\text { Técnicas } \\
\text { de } \\
\text { Gestão. }\end{array}$ & $\begin{array}{c}\text { Técnicas } \\
\text { de } \\
\text { Gestão } \\
\text { Ambiental. }\end{array}$ & $\begin{array}{l}\text { Organização } \\
\text { do } \\
\text { Trabalho. }\end{array}$ & \begin{tabular}{|l|} 
Relações \\
Externas.
\end{tabular} & $\begin{array}{l}\text { Conceitos/Estratégias } \\
\text { de Marketing. }\end{array}$ & $\begin{array}{c}\text { Estética, } \\
\text { Desenho } \\
\text { ou } \\
\text { outras } \\
\text { mudanças. }\end{array}$ \\
\hline $\begin{array}{ll}\text { Fabricação } & \text { de } \\
\text { coque, } & \text { de } \\
\text { produtos } & \\
\text { derivados } & \text { do } \\
\text { petróleo } & \\
e & \text { de } \\
\text { biocombustíveis. }\end{array}$ & 286 & 146 & 48 & 47 & 37 & 31 & 24 & 9 \\
\hline $\begin{array}{l}\text { Fabricação de } \\
\text { coque e } \\
\text { biocombustíveis } \\
\text { (álcool e outros). }\end{array}$ & 204 & 106 & 35 & 36 & 24 & 10 & 11 & 7 \\
\hline $\begin{array}{l}\text { Refino de } \\
\text { petróleo. }\end{array}$ & 82 & 41 & 13 & 11 & 12 & 20 & 13 & 2 \\
\hline
\end{tabular}

Tabela 1 - elaborada pelo Autor / Pesquisa de Inovação Tecnológica 2008. p. 130-131.

A Tabela 1, nas Inovações Organizacionais, período 2006-2008, destaca que de 286 empresas de fabricação de coque, de produtos derivados do petróleo e de combustíveis, $51.45 \%$ (146) não implementaram produto ou processo e sem projetos. Inovações de Técnicas de Gestão, que engloba Gestão do Conhecimento, foram feitas por até 48 empresas. Na fabricação de coque e biocombustíveis (álcool e outros), de 204 empresas, 106 (51.96\%) não implementaram produto ou processo e sem projetos. Inovações de Técnicas de Gestão foram agenciadas por até 35 das empresas. No refino de petróleo, de 82 empresas, 41 (50\%) não implementaram produto ou processo e sem projetos. Inovações de Técnicas de Gestão foram realizadas por até 13 das empresas.

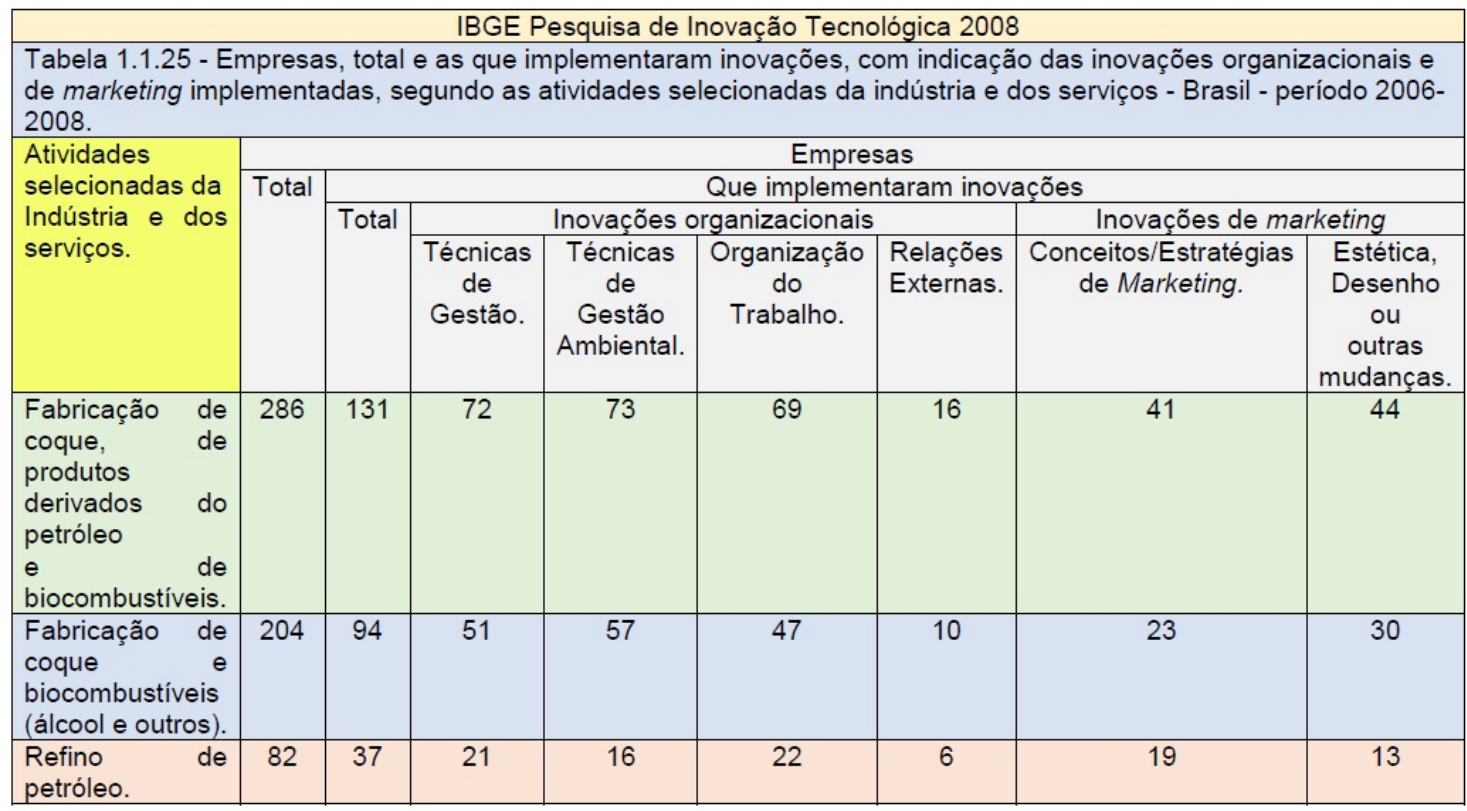

Tabela 2 - elaborada pelo Autor / Pesquisa de Inovação Tecnológica 2008. p. 132-133.

A Tabela 2 destaca, nas Inovações Organizacionais, período 2006-2008, que de 286 empresas de fabricação de coque, de produtos derivados do petróleo e de combustíveis, 45.80\% (131) implementaram inovações. Deste modo, inovações de técnicas de gestão 
foram feitas por até 72 das empresas. Na fabricação de coque e biocombustíveis (álcool e outros) há: de 204 empresas, 94 (46.08\%) implementaram inovações. Já inovações de técnicas de gestão foram realizadas por até 51 das empresas. No contexto do refino de petróleo, de 82 empresas, inovações ocorreram em 37 (45.12\%). Assim, inovações de técnicas de gestão foram agenciadas por até 21 das empresas.

\begin{tabular}{|c|c|c|c|c|c|c|c|c|}
\hline \multicolumn{9}{|c|}{ IBGE Pesquisa de Inovação Tecnológica 2008} \\
\hline \multicolumn{9}{|c|}{$\begin{array}{l}\text { Tabela 1.1.26 - Empresas, total e as que não implementaram inovações e com projetos, com indicação das } \\
\text { inovações organizacionais e de marketing implementadas, segundo as atividades selecionadas da indústria e dos } \\
\text { serviços - Brasil - período } 2006-2008\end{array}$} \\
\hline \multirow{4}{*}{$\begin{array}{l}\text { Atividades } \\
\text { selecionadas da } \\
\text { Indústria e dos } \\
\text { serviços. }\end{array}$} & \multicolumn{8}{|c|}{ Empresas } \\
\hline & \multirow[t]{3}{*}{ Total } & \multicolumn{7}{|c|}{ Que não implementaram inovações e com projetos } \\
\hline & & \multirow[t]{2}{*}{ Total } & \multicolumn{4}{|c|}{ Inovações organizacionais } & \multicolumn{2}{|c|}{ Inovações de marketing } \\
\hline & & & $\begin{array}{l}\text { Técnicas } \\
\text { de } \\
\text { Gestão. }\end{array}$ & $\begin{array}{l}\text { Técnicas } \\
\text { de } \\
\text { Gestão } \\
\text { Ambiental. }\end{array}$ & $\begin{array}{l}\text { Organização } \\
\text { do } \\
\text { Trabalho. }\end{array}$ & $\begin{array}{l}\text { Relações } \\
\text { Externas. }\end{array}$ & $\begin{array}{c}\text { Conceitos/Estratégias } \\
\text { de Marketing. }\end{array}$ & $\begin{array}{c}\text { Estética, } \\
\text { Desenho } \\
\text { ou } \\
\text { outras } \\
\text { mudanças. }\end{array}$ \\
\hline $\begin{array}{ll}\text { Fabricação } & \text { de } \\
\text { coque, } & \text { de } \\
\text { produtos } & \\
\text { derivados } & \text { do } \\
\text { petróleo } & \\
e & \text { de } \\
\text { biocombustíveis. }\end{array}$ & 286 & 9 & 1 & 4 & 4 & 1 & 3 & - \\
\hline $\begin{array}{l}\text { Fabricação de } \\
\text { coque e } \\
\text { biocombustíveis } \\
\text { (álcool e outros). }\end{array}$ & 204 & 4 & 1 & 2 & - & 1 & - & - \\
\hline $\begin{array}{ll}\text { Refino } & \text { de } \\
\text { petróleo. }\end{array}$ & 82 & 4 & - & 1 & 4 & - & 3 & - \\
\hline
\end{tabular}

Tabela 3 - elaborada pelo Autor / Pesquisa de Inovação Tecnológica 2008. p. 134-135.

A Tabela 3 indica, nas Inovações Organizacionais, período 2006-2008, que de 286 empresas de fabricação de coque, de produtos derivados do petróleo e de combustíveis, 3.15\% (9) não implementaram inovações, mas apresentaram-se com projetos. Por sua vez, Inovações de Técnicas de Gestão foram feitas por até 1 das empresas.

No que diz respeito à fabricação de coque e biocombustíveis (álcool e outros) há o seguinte: de 204 empresas, 4 (1.96\%) não implementaram inovações, mas apresentaram-se com projetos. No que concerne a Técnicas de Gestão, inovações foram realizadas por até 1 das empresas.

No cenário do refino de petróleo, de 82 empresas, 4.88\% (4) não implementaram inovações, mas apresentaram-se com projetos. Inovações de Técnicas de Gestão não foram indicadas. 


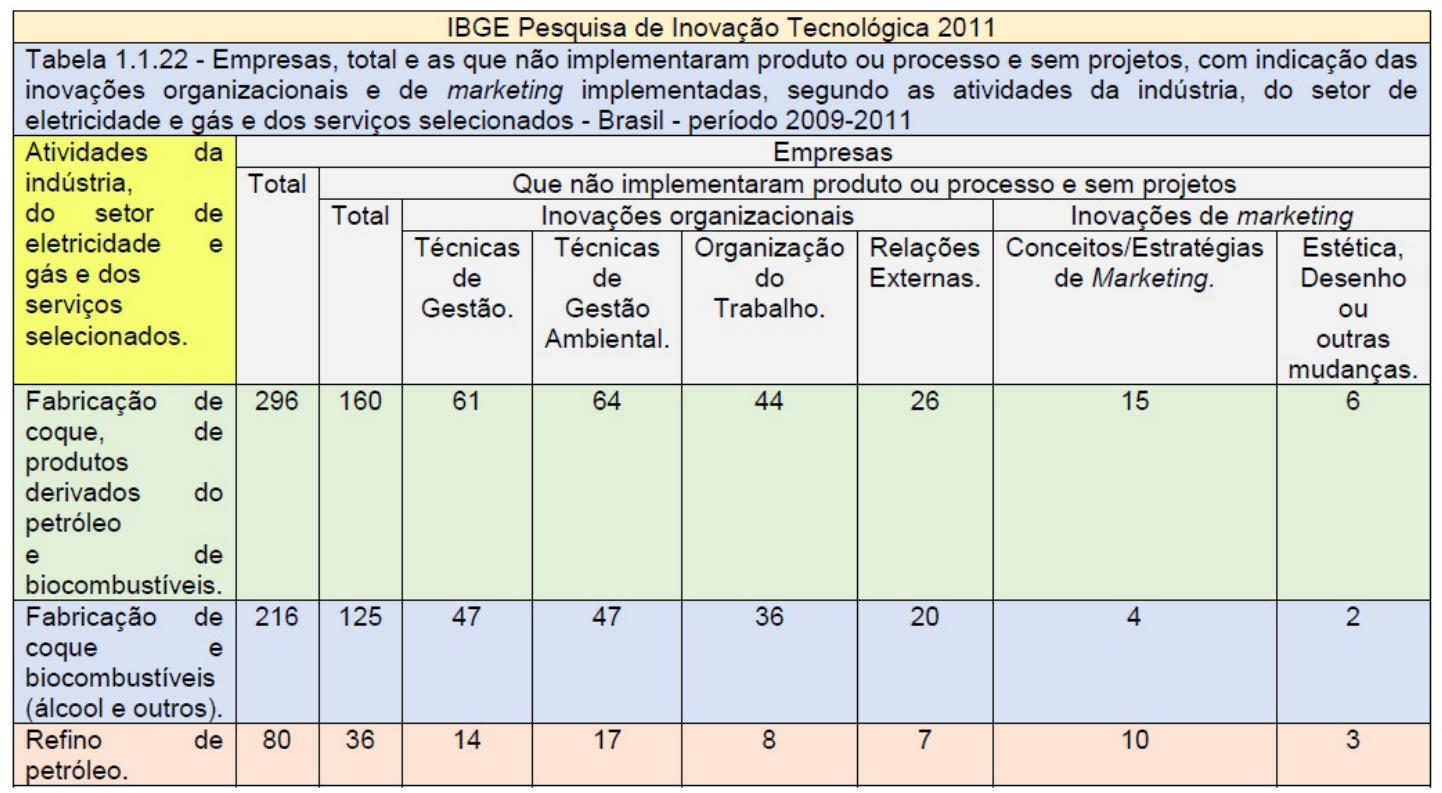

Tabela 4 - elaborada pelo Autor / Pesquisa de Inovação 2011. p. 181-183.

A Tabela 4 indica, em particular quanto às Inovações Organizacionais, período 20092011, que de 296 empresas de fabricação de coque, de produtos derivados do petróleo e de combustíveis, $54.05 \%$ (160) não implementaram produto ou processo e apresentaram-se sem projetos. Por sua vez, no que diz respeito às Inovações de Técnicas de Gestão, estas foram feitas por até 61 das empresas. No que concerne à fabricação de coque e biocombustíveis (álcool e outros) temos: de 216 empresas, 125 (57.87\%) não implementaram produto ou processo e apresentaram-se sem projetos. No que remete às Técnicas de Gestão, inovação ocorreu em até 47 das empresas. No que se refere ao refino de petróleo, de 80 empresas, 45\% (36) não implementaram produto ou processo e apresentaram-se sem projetos. Inovações de Técnicas de Gestão foram agenciadas por até 14 das empresas.

\begin{tabular}{|c|c|c|c|c|c|c|c|c|}
\hline \\
\hline \multicolumn{9}{|c|}{$\begin{array}{l}\text { IBGE Pesquisa de Inovação Tecnológica } 2011 \\
\text { Tabela 1.1.23 - Empresas, total e as que implementaram inovações, com indicação das inovações organizacionais e } \\
\text { de marketing implementadas, segundo as atividades da indústria, do setor de eletricidade e gás e dos serviços } \\
\text { selecionados - Brasil - período } 2009-2011\end{array}$} \\
\hline \multirow{4}{*}{$\begin{array}{lr}\text { Atividades } & \text { da } \\
\text { indústria, } & \\
\text { do setor de } \\
\text { eletricidade e } \\
\text { gás e dos } \\
\text { serviços } \\
\text { selecionados. }\end{array}$} & \multirow{4}{*}{ Total } & \multicolumn{7}{|c|}{ Empresas } \\
\hline & & \multicolumn{7}{|c|}{ Que implementaram inovações } \\
\hline & & \multirow[t]{2}{*}{ Total } & \multicolumn{4}{|c|}{ Inovações organizacionais } & \multicolumn{2}{|c|}{ Inovações de marketing } \\
\hline & & & $\begin{array}{c}\text { Técnicas } \\
\text { de } \\
\text { Gestão. }\end{array}$ & $\begin{array}{l}\text { Técnicas } \\
\text { de } \\
\text { Gestão } \\
\text { Ambiental. }\end{array}$ & $\begin{array}{c}\text { Organização } \\
\text { do } \\
\text { Trabalho. }\end{array}$ & $\begin{array}{l}\text { Relações } \\
\text { Externas. }\end{array}$ & $\begin{array}{c}\text { Conceitos/Estratégias } \\
\text { de Marketing. }\end{array}$ & $\begin{array}{l}\text { Estética, } \\
\text { Desenho } \\
\text { ou } \\
\text { outras } \\
\text { mudanças. }\end{array}$ \\
\hline $\begin{array}{lr}\text { Fabricação } & \text { de } \\
\text { coque, } & \text { de } \\
\text { produtos } & \\
\text { derivados } & \text { do } \\
\text { petróleo } & \\
e & \text { de } \\
\text { biocombustíveis. }\end{array}$ & 296 & 113 & 92 & 76 & 63 & 39 & 19 & 24 \\
\hline $\begin{array}{l}\text { Fabricação de } \\
\text { coque e } \\
\text { biocombustíveis } \\
\text { (álcool e outros). }\end{array}$ & 216 & 69 & 60 & 52 & 48 & 16 & 4 & 4 \\
\hline $\begin{array}{l}\text { Refino de } \\
\text { petróleo. }\end{array}$ & 80 & 43 & 31 & 24 & 16 & 23 & 14 & 20 \\
\hline
\end{tabular}

Tabela 5 - elaborada pelo Autor / Pesquisa de Inovação 2011. p. 185-187.

A Tabela 5 apresenta, em especial acerca de Inovações Organizacionais, período 2009-2011, que de 296 empresas de fabricação de coque, de produtos derivados do 
petróleo e de combustíveis, 38.17\% (113) implementaram inovações. No que remete às Técnicas de Gestão, inovações foram feitas por até 92 das empresas. No que concerne à fabricação de coque e biocombustíveis (álcool e outros) temos: de 216 empresas, 69 (31.94\%) implementaram inovações. Relativa às Técnicas de Gestão, inovação ocorreu em até 60 empresas. Ao nos determos no refino de petróleo, de 80 empresas, 53.75\% (43) implementaram inovações. Inovações de Técnicas de Gestão foram realizadas por até 31 das empresas.

\begin{tabular}{|c|c|c|c|c|c|c|c|c|}
\hline & & & IBGE & esquisa de & novação Tecn & lógica 201 & & \\
\hline $\begin{array}{l}\text { Tabela } 1.1 .24- \\
\text { inovações organ } \\
\text { eletricidade e gás }\end{array}$ & & $\begin{array}{l}\text { S, to } \\
\text { sviço }\end{array}$ & $\begin{array}{l}\text { e as } \\
\text { mark } \\
\text { selecion }\end{array}$ & $\begin{array}{l}\text { ue não in } \\
\text { ing implen } \\
\text { dos - Brasi }\end{array}$ & $\begin{array}{l}\text { mentaram ir } \\
\text { adas, segur } \\
\text { eríodo 2009 }\end{array}$ & $\begin{array}{l}\text { ovações e } \\
\text { do as ati } \\
2011\end{array}$ & $\begin{array}{l}\text { com projetos, com i } \\
\text { idades da indústria, }\end{array}$ & $\begin{array}{l}\text { ação das } \\
\text { setor de }\end{array}$ \\
\hline Atividades da & & & & & Empre & & & \\
\hline indústria, & Total & & & Que não & implementaral & inovações & e com projetos & \\
\hline do setor & & Total & & Inovações & rganizacionais & & Inovações de ma & keting \\
\hline $\begin{array}{l}\text { eletricidade } \\
\text { gás e dos } \\
\text { servicos } \\
\text { selecionados. }\end{array}$ & & & $\begin{array}{l}\text { Técnicas } \\
\text { de } \\
\text { Gestão. }\end{array}$ & $\begin{array}{c}\text { Técnicas } \\
\text { de } \\
\text { Gestão } \\
\text { Ambiental. }\end{array}$ & $\begin{array}{c}\text { Organização } \\
\text { do } \\
\text { Trabalho. }\end{array}$ & $\begin{array}{l}\text { Relações } \\
\text { Externas. }\end{array}$ & $\begin{array}{c}\text { Conceitos/Estratégias } \\
\text { de Marketing. }\end{array}$ & $\begin{array}{c}\text { Estética, } \\
\text { Desenho } \\
\text { ou } \\
\text { outras } \\
\text { mudancas. }\end{array}$ \\
\hline $\begin{array}{ll}\text { Fabricação } & \text { de } \\
\text { coque, } & \text { de } \\
\text { produtos } & \\
\text { derivados } & \text { do } \\
\text { petróleo } & \\
\text { e } & \text { de } \\
\text { biocombustíveis. }\end{array}$ & 296 & 23 & 6 & 11 & 3 & - & 3 & 1 \\
\hline $\begin{array}{l}\text { Fabricação de } \\
\text { coque } \\
\text { biocombustíveis } \\
\text { (álcool e outros). }\end{array}$ & 216 & 22 & 5 & 10 & 3 & - & 2 & 1 \\
\hline $\begin{array}{ll}\text { Refino } & \text { de } \\
\text { petróleo. } & \end{array}$ & 80 & 1 & 1 & 1 & - & - & 1 & - \\
\hline
\end{tabular}

Tabela 6 - elaborada pelo Autor / Pesquisa de Inovação 2011. p. 189-191.

A Tabela 6 ressalta, notadamente quanto a Inovações Organizacionais, período 20092011, que de 296 empresas de fabricação de coque, de produtos derivados do petróleo e de combustíveis, 7.77\% (23) não implementaram inovações, mas apresentaram-se com projetos. Neste cenário, no que concerne às Inovações pertinentes a Técnicas de Gestão, estas foram feitas por até 6 das empresas. Nas empresas com fabricação de coque e biocombustíveis (álcool e outros) há: de 216 empresas, 22 (31.94\%) não implementaram inovações, mas apresentaram-se com projetos. No que diz respeito a Técnicas de Gestão, inovação ocorreu em até 5 das empresas. Já no refino de petróleo, de 80 empresas, 1 empresa (1.25\%) não implementou inovação, mas apresentou-se com projetos. Inovações de Técnicas de Gestão foi realizada por até 1 das empresas.

Em vista do assinalado de cada uma das seis Tabelas, significativo é ressaltar que a Série PINTEC/IBGE, Pesquisa de corte transversal (IBGE, 2013, p. 12-13), visa elaborar Indicadores setoriais, regionais e também nacionais quanto a atividades de inovação em empresas do Setor da Indústria, bem como Indicadores nacionais de inovação em empresas dos setores de Eletricidade e Gás, incluindo Serviços selecionados - em equilíbrio com Recomendações internacionais: metodologia e conceitos. Deste modo, os Indicadores gerados, de uso de empresas (análise do mercado) e de associações de classe (análise de desempenho), servem de parâmetro para o desenvolvimento e avaliação de Políticas Públicas tanto nacionais quanto regionais.

PINTEC - Pesquisa de Inovação Tecnológica 2008 e Pesquisa de Inovação 2011 
A PINTEC se articula com pesquisas estruturais de subsistemas de estatísticas industrias e de serviços do Brasil. Deste modo, compreende-se o porquê de não haver dados precisos acerca de qual Inovação Organizacional foi realizada. O Instrumento de Pesquisa, o Questionário PINTEC/IBGE, de forma objetiva investiga se houve ou não inovação organizacional, ou seja, resposta sim ou não - novas técnicas de gestão, novas técnicas de gestão ambiental, novos métodos de organização do trabalho e mudanças significativas nas relações com outras empresas e instituições (IBGE, 2013, p. 217).

Assim, será no processo de pesquisa, análise e avaliação de inovação organizacional, no ambiente de intrafirma, que a precisão acerca da inovação será de fato apreendida. Importante destacar que o contexto das Inovações Organizacionais, apresentado pela Série PINTEC/IBGE, para a sua melhor leitura, também deve levar em conta e se articular com dados e sínteses que a Série compartilha acerca de outras Variáveis da Pesquisa. Exemplo: gastos com as atividades inovativas; arranjos cooperativos estabelecidos; obstáculos encontrados às atividades de inovação.

Deste modo, o que se assinala pela Tabela 1 é o alto percentual de empresas, em torno de $50 \%$ em cada um dos três Segmentos, que não implementaram produtos ou processos e sem que possuíssem projetos. Mas há um certo equilíbrio quantitativo de inovações organizacionais dentre empresas de fabricação de coque, de produtos derivados do petróleo e de biocombustíveis. A Tabela 2, que também contempla empresas que implementaram inovações, assinala significativo quantitativo de empresas que inovaram no quesito Técnicas de Gestão, em especial empresas de fabricação de coque, de produtos derivados do petróleo e de biocombustíveis - apesar do distanciamento do número total de empresas. Observa-se que possíveis indicações macro de não inovações podem retratar, quanto ao contexto intrafirma, que as condições existentes já eram ou são relevantes quanto à Gestão do Conhecimento. A Tabela 3, que indica empresas que não inovaram, mas que tinham projetos de inovação, ressalta baixíssimo quantitativo de empresas que inovaram nas Técnicas de Gestão - quase nulo.

A Tabela 4, que inicia o período de 2011, apresenta alto percentual de empresas, em torno de $45 \%$ a 55\%, que não implementaram produtos ou processos e que não possuíam, na ocasião, projetos. No que diz respeito aos três segmentos produtivos, as inovações em técnicas de gestão indicam um equilíbrio quantitativo com inovação em técnicas de gestão ambiental - apesar de valores totais diferenciados de cada Segmento. A Tabela 5, contexto de empresas que inovaram, apresenta maior relevância quantitativa em inovação de técnicas de gestão no cenário do refino do petróleo. Importante destacar que não se sabe quais inovações foram feitas em cada empresa e nem mesmo como é a realidade de suas técnicas de gestão - que podem já possuir alto patamar de gestão do conhecimento. A Tabela 6, que concerne a empresas que não implementaram inovações, mas que tinham projetos, nos informa que quanto às inovações houve inexpressivo quantitativo de inovações em técnicas de gestão.

Por fim, o mero quantitativo de inovação organizacional ou não, em cada Segmento, em particular técnicas de gestão, por si só não retrata a complexidade das realizações de inovação em questão. Somente o diagnóstico sistêmico intrafirma é que será de fato capaz de indicar o quanto se avançou ou não e com qual qualidade e profundidade nas inovações organizacionais.

A Indústria Internacional de Petróleo, Gás Natural e Biocombustíveis e o Brasil 
O Setor de Energia do Brasil - Petróleo, Gás e Biocombustíveis - passa por intensas mudanças no ambiente de negócio, já a partir de 2014, por variáveis internas do País e externas, ou seja, do Mercado Internacional de Petróleo e de geopolítica global.

Ao focalizarmos com precisão a questão shale gas - gás de áreas não convencionais - além das fronteiras dos Estados Unidos, Almeida (2014, p. 26) destaca aspectos relacionados aos modelos regulatório e de negócio pertinentes à exploração em tela e as dimensões de recursos humanos, tecnológicos e financeiros disponíveis ao shale gas. Em vista disto, ressalta que a grande questão, em aberto, acerca do futuro de mercado internacional de energia, vincula-se ao shale gas. Isto fica ainda mais acentuado quando a própria Agência Internacional de Energia (AIE) assinala a significativa disponibilidade de shale gas na China, na Argentina, no México, na África do Sul, na Austrália e no próprio Brasil. Neste cenário, a AIE em especial ressalta a difusão do shale gas na China, na Argentina e na Índia - após 2020. De igual modo, afirma que até 2035 será dos recursos não convencionais que teremos a metade do crescimento da produção de gás - notadamente shale gas e coalbed methane (gás de carvão).

Em vista disto, necessário é destacar as condições de sucesso da exploração do shale gas dos Estados Unidos e que não estão presentes em demais países: grande conhecimento geológico nos Estados Unidos e Canadá; regulação leve no segmento do upstream, convencional e não convencional, inclusive quanto ao processo de licenciamento; propriedade dos recursos do subsolo pertencente ao proprietário do solo; desburocratização quanto a terras públicas; existência de mais de dez mil empresas da Indústria do Óleo \& Gás; aceitação social quanto à atividade de exploração não convencional, em especial no Sul e Meio Oeste dos Estados Unidos; extensa rede de gasodutos e de distribuição e transporte; liberalização do Mercado e sofisticação do mercado financeiro; exploração por parte de pequenas e independentes empresas especializadas no cenário do gás não convencional. (ALMEIDA, 2014. p. 27)

Neste contexto, no que diz respeito à China, a Agência Internacional de Energia ressalta que este País possui o maior volume de shale gas do mundo. De igual modo, apresenta-se como um grande importador - incluindo o gás natural liquefeito (GNL). Deste modo, para reduzir a sua dependência externa quanto ao gás natural e para reduzir o consumo de carvão, a China apresentou um plano quinquenal (no caso seria para até 2015) que visava dobrar a participação do gás natural em sua Matriz Energética. Para tanto, produziria em torno de 260 bilhões de metros cúbicos, sendo que 6.5 bilhões seriam alcançados mediante produção de shale gas. Neste cenário, relevante é apontar que a China já tem produção de tight gas e de coalbed methane - CBM (gás de carvão), ou seja, possui condições técnicas internas (incluindo fornecedores) para a exploração de shale gas, além de já possuir uma significativa indústria onshore. Este aprendizado tecnológico acentuou-se mediante Acordos de cooperação técnica com os Estados Unidos. Isto incentivou que empresas chinesas de petróleo adquirissem participações em empresas operadores e fornecedoras norte-americanas. Em contraposição ao cenário norte-americano, o contexto chinês apresenta dificuldades e desafios quanto à exploração do shale gas, em especial: baixo conhecimento geológico das áreas de shale; pouco desenvolvimento de infraestrutura de escoamento e transporte de gás; regulação inadequada da Indústria local - controle de preços domésticos por parte do Governo e ausência de liberação do próprio Mercado. (ALMEIDA, 2014. p. 29-30)

Assim, quanto ao mercado internacional de gás natural, Losekann e Almeida (2014, p. 24) esclarecem que o gás natural sempre foi agenciado como um produto pouco atrativo por empresas que focalizam o petróleo. Somente com a recente ampliação do 
gás natural no consumo é que esta visão tem sido alterada. Como resultado, o portfólio de Operadoras já apresenta significativo aumento deste ativo. Estamos, então, na era do gás. Neste sentido, rápido crescimento da oferta de gás ocorreu no período 2000-2013, em especial por parte de países da Organização para Cooperação e Desenvolvimento Econômico (OCDE) - como Estados Unidos e Austrália. A partir de alta oferta interna, o preço do gás norte-americano caiu acentuadamente. Em paralelo, em demais Mercados, como o Europeu e o Asiático, houve aumento do preço do gás. Deste modo, os Estados Unidos conquistaram vantagem competitiva - que foi fundamental para a sua recuperação econômica no contexto de sua última grande crise financeira.

Em vista disto, levando-se em conta as grandes mudanças do quadro internacional de petróleo e gás, o Brasil, conforme Losekann e Almeida (2014, p. 25-26), será impactado tanto a curto prazo quanto a longo prazo. Assim, relevante assinalar que o Brasil precisa investir, ao ano, cerca de US\$ 50 bilhões. Isto significa maior demanda sobre a Petrobras - por ser esta, então, a única operadora do Pré-sal. Torna evidente, então, que fica muito mais sensível a questão do fluxo de caixa da Empresa para que se evite, inclusive e ao máximo, deterioração da capacidade de investimentos da Estatal. A questão que se apresenta, como algo fundamental, diz respeito à atratividade dos investimentos no Setor de Exploração e Produção (E\&P) - não se esquecendo de que México e Argentina têm feito significativos esforços pragmáticos para captar investimentos externos. Por conseguinte, aspectos Regulatórios precisam de melhor e mais amplo debate, integrando a este Painel a questão da Política de Conteúdo Local, além da Política de Preços de Derivados, da Tributação sobre Investimentos e das Rodadas de Licitação. Vale citar, também, que as expectativas de gás natural do Pré-sal apresentaram-se menos favoráveis do que era inicialmente previsto e que o Contrato de Importação de Gás da Bolívia encerra-se em 2019 - cujas expectativas de Reservas não se apresentam favoráveis. O contexto de alta incerteza quanto ao gás natural no Brasil compromete investimentos tanto na Indústria quanto na geração termelétrica.

Neste sentido, constantes mudanças de Política Setorial do Brasil, ou seja, ausência de linearidade de Políticas Públicas, não têm favorecido o esforço exploratório e nem a capacidade de produção nacional. No contexto histórico, ao longo da última década de 90, o consumo de gás natural no Brasil representou, no máximo, 4\% da oferta de Energia. Com o gasoduto Bolívia-Brasil (Santa Cruz de La Sierra às Regiões Sul, Sudeste e Centro-Oeste do Brasil), a partir de 1999, o consumo interno cresceu à taxa média de $15 \%$ ao ano - no ano de 2000 o Setor Industrial do Brasil consumia 74\% deste gás. Em 2014, mediante importações e por decorrência de produção interna, o gás natural passou a representar 12\% da nossa Matriz Energética. Todavia, há a ressalva de que os interesses da indústria de gás natural, do Brasil, sempre se viram subordinados a distintas necessidades do Setor Elétrico do País. (COLOMER, 2014. p. 40-41)

Por fim, destaca-se que há diferenças entre produção em formações convencionais e em não convencionais. Formações de shale e tight gas indicam rápido período de recuperação. Isto significa que o fluxo de produção no escopo convencional pode manter-se de 15 a 30 anos, enquanto um poço não convencional tem a sua maior parte produtiva correlacionada aos primeiros 3 anos. Assim, obriga-se o não convencional a um contínuo investimento em Exploração e Produção - o que o torna mais sensível a preços tanto do gás natural quanto do líquido de gás natural. (COLOMER, 2014. p. 32).

\section{Gestão Organizacional e a Gestão do Conhecimento}


A gestão organizacional está de forma intrínseca conectada à gestão estratégica. Deste modo, Serra et al. (2014, p. 5) pontuam que estratégia diz respeito à ação ou às ações que tomadores de decisão agenciam para que objetivos da empresa ou da instituição sejam conquistados. Com isto, gestão estratégica diz respeito à identificação de estratégias que executivos assumem para que se possa atingir tanto um nível superior de desempenho, incluindo a comparação com indicadores de concorrentes e do Mercado em si, e de vantagem competitiva. Nesse contexto, além de questões internas, como recursos humanos de alta qualificação, capacidade de inovação e cultura organizacional inserida no trabalho conjunto e integrado, fatores externos, como políticos e macroeconômicos, por sua vez, afetam a efetividade da gestão do Negócio.

Neste contexto, Rodriguez y Rodriguez (2013, p.5-6) ressalta que a Petrobras, em 2008, evidenciou a necessidade de colher propostas com vistas à implantação de Gestão do Conhecimento (GC) na área de Gás e Energia. Assim, com a participação de mais de 20 empresas vinculadas ao Grupo Interativo de Gestão do Conhecimento e Inovação (GIGCI), constatou-se que não havia, no Mercado, consenso sobre a implantação da GC nas empresas - uma vez que havia distintos entendimentos sobre o Tema, ou seja, Gestão do Conhecimento relacionada: à implantação da gestão por competências; ao conhecimento requerido pelos processos de negócio; ao treinamento ou capacitação.

Em vista disto, mediante pensamento sistêmico, o GIGCI investigou 5 dimensões para sedimentar conceitos e estruturas da Gestão do Conhecimento: definição de estratégia empresarial vinculada à Gestão do Conhecimento e Inovação (GCI); fatores da cultura organizacional que facilitam e/ou dificultam o desenvolvimento da GCI; definição do modelo de gestão voltado à GCI; identificação de práticas de GCI que agregam valor à empresa; identificação de tecnologias de colaboração e estruturação do conhecimento organizacional; identificação de indicadores e métricas que reflitam resultados construídos por ações de GCI. (RODRIGUEZ Y RODRIGUES, 2013. p.8-9)

Assim, a criação de equipes interdisciplinares e interorganizacionais colaborativas, em especial via organização orgânica (premissas não mecânicas), por exemplo, permite: criar ambiente de comunicação que motive pessoas; aplicar melhores práticas de gestão e soluções de problemas; valorizar pessoas por sua criatividade e poder de inovação; conhecer as competências existentes na organização e acioná-las internamente; reduzir custos de atividades e de projetos pela economia de tempo de aprendizagem. Toda esta dinâmica precisa ser agenciada por canais de confiança, respeito e via ações sedimentadas em valores coletivos. (RODRIGUEZ Y RODRIGUES, 2013. p.19-20)

Neste contexto, Carvalho (2012, p. 100) ressalta que dentre os aspectos conceituais voltados à Base de Conhecimento, ou seja, o modelo de armazenamento de tudo que a organização pode deter em termos de conhecimento, relevante é se considerar: que o conhecimento apresenta características orgânicas de mutação e de evolução, diga-se, não é algo estático no tempo; as dinâmicas de combinação e recontextualização que criam conhecimento são limitadas pela criatividade dos que a manipulam - não por fatores deterministas; a Base de Conhecimento não é, então, algo pronto ou completo, significando que a sua estrutura precisa ser flexível e adaptável às condições do ambiente. Esta mesma Base é edificada, por fim, por mapas mentais e concretos que propiciem à pessoa, inclusive, ir ao encontro do conhecimento da forma mais rápida e segura possível,

\section{A Petrobrás e a Gestão do Conhecimento}


A Petrobrás (2015, p. 135), quanto a sistemas computacionais vinculados a macroprocessos finalísticos e objetivos estratégicos, destaca possuir processo de levantamento de necessidades de Tecnologia da Informação e Comunicação (TIC), o qual se conclui com a confecção do Plano Anual de Investimentos: só com este Plano aprovado é que necessidades são aprovadas para o ano seguinte. Na execução de novo sistema há o projeto PPO-SGO (Planejamento e Programação da Operação - Sistema de Gestão do Parque Gerador da Petrobras) - Contratação e Implantação. Neste contexto, na gerência de Planejamento e Programação da Operação não havia indicação de sistema unificado que atendesse às atividades de forma eficiente, dificultando: programação integrada da geração de energia e vapor; planejamento e acompanhamento de intervenções; acompanhamento de operação em tempo real; apuração de resultados obtidos. Houve a identificação da Gerência utilizar controles manuais, planilhas eletrônicas, $e$-mails e ligações telefônicas para a realização de controle das Operações de Energia. Em paralelo, há práticas não corretivas, ou seja, manutenções evolutivas como o projeto Manutenção Evolutiva do OGME (Open Utilities - Gestão de Mercados de Energia) para melhorias no Sistema de Informação OGME: foco em se adequar a mudanças de Regulamentação do Mercado de Comercialização de Energia Elétrica.

Neste contexto, a Petrobras (2015), Informativo Fatos e Dados, destaca que a Gestão do Conhecimento é processo de criação de valor para o Negócio, pois busca identificar, criar e preservar, além de compartilhar e aplicar conhecimentos necessários para a realização de processos e projetos. Assim, desde 2000, iniciativas como o Programa Mentor Petrobras, passagem de conhecimento estruturado dos mais experientes aos mais novos, bem como o Rodízio Técnico, deslocamento temporário do funcionário para outras gerências, têm sido realizadas. Também há a ação Lições Aprendidas pela qual ocorre a identificação, o registro e a disseminação do conhecimento a partir de experiências anteriores, bem como a disseminação do Conhecimento pelo aprendizado por observação e via programas de desenvolvimento profissional no Exterior.

Nesta dinâmica, o Centro de Pesquisas Leopoldo Américo Miguez de Mello CENPES, em 2014, recebeu R\$ 1.7 bilhão em recursos. O Centro finalizou o ano com 752 projetos de Pesquisa e Desenvolvimento (P\&D). Estes Projetos originam-se de conjunto de processos coordenados por Comitês que estabelecem os direcionadores, bem como de desafios tecnológicos a serem superados. Este processo atende a objetivos específicos e ao cumprimento do Plano de Negócios e Gestão da Empresa via prazos pré-fixados. O CENPES conta com 1.862 empregados, sendo que 1.384 voltados à $\mathrm{P} \& \mathrm{D}$ e 309 à Engenharia Básica dos projetos. Assim, 32\% dos pesquisadores têm título de mestrado e 17\% de doutorado. (PETROBRAS, 2015, p. 20-21)

O CENPES se articula com mais de 100 universidades e instituições de pesquisa do Brasil e do Exterior, além de parcerias com fornecedores e outros agentes. Os benefícios da Inovação se expandem pela sociedade pelo fortalecimento da indústria e cadeia produtiva local, bem como pela redução de necessidade de importação de petróleo, derivados e equipamentos, além de diminuir emissões e particulados na atmosfera. Um significativo resultado desta dinâmica é, por exemplo, o desenvolvimento de método de redirecionamento da injeção de gás em coluna de produção em poços com gás lift. Isto permite a redução da perda de carga no ponto de injeção de gás. Há, assim, ganhos de produção de $2 \%$ a $3 \%$ em poços de média e alta pressão. (PETROBRAS, 2015, p. 2021)

\section{Conclusão}


No Offshore, no cenário de intensa redução do preço do barril do petróleo no mercado internacional, a inovação organizacional que dinamiza novas técnicas de gestão, em especial a vinculada à Gestão do Conhecimento, apresenta-se como fundamental aspecto de competitividade para a Indústria de petróleo, gás natural e biocombustíveis. Assim, quanto a essa Gestão, algo que se deve conhecer diz respeito a como o Conhecimento é agenciado e potencializado como ativo estratégico no upstream (exploração e produção) e no downstream (escoamento, refino, transporte, distribuição e revenda). Isto é ainda mais relevante quando se sabe que a Pesquisa e Desenvolvimento assume papel imprescindível no Programa de Investimentos e no Plano de Negócios e Gestão da Petrobras.

Deste modo, conhecer da Petrobras o Modelo de Gestão do Conhecimento e Inovação (MGCI) adotado e a estrutura dos processos também é significativo para que se possa melhor apreender o Sistema de Conhecimento e Inovação (SCI) da Empresa. Em vista disto, questão que se apresenta correlaciona-se a como os diversos sistemas computacionais vinculados a macroprocessos finalísticos e a objetivos estratégicos, em processo de implementação e os com status de aperfeiçoamento, agregam valor às capacitações e capacidades da Petrobras ao longo das etapas de criar, reter, disseminar, aplicar, desenvolver e proteger o conhecimento organizacional - a partir, inclusive, de dados e informações e de conhecimentos tácitos e explícitos em dinâmica de conversão.

Neste sentido, uma outra questão vincula-se a se saber como as ações Programa Mentor Petrobras, Rodízio Técnico e Lições Aprendidas, dentre outras, respondem a uma parte dos desafios demandados por um contexto de negócio que insere R $\$ 77$ bilhões/ano de investimentos e que representa 12\% do Produto Interno Bruto do País, além de previsão, até o ano de 2020, de R\$ 950 bilhões de investimentos e gastos diretos na cadeia de bens e serviços em petróleo e gás. Assim, necessário é investigar como as três Ações citadas e outras que são postas em prática pela Empresa, quanto à Gestão do Conhecimento, de fato integram e potencializam ativos estratégicos nas várias unidades e áreas, bem como setores da Petrobras - especificamente nos segmentos de fabricação de coque, de produtos derivados do petróleo e de combustíveis; à fabricação de coque e biocombustíveis (álcool e outros); ao refino do petróleo.

Nesta dinâmica, no que diz respeito ao Centro de Pesquisas Leopoldo Américo Miguez de Mello - CENPES e aos seus mais de 700 projetos em Pesquisa e Desenvolvimento, referência ano de 2014, o que precisa ser investigado e analisado é, no cenário deste Artigo, como o CENPES se apresenta responsivo perante a necessidade de inovação organizacional e como esta Inovação agenciada por este Centro de Pesquisa transborda para o Sistema Petrobras - em particular mediante a Gestão do Conhecimento. Deste modo, questão importante refere-se aos riscos do processo inovativo e à destruição criativa para que a Empresa possa ter condições efetivas de lidar com a concorrência internacional, expandir-se e se inserir em novos mercados, além de reduzir os seus custos em serviços e produtos. É evidente que neste quadro, além de variáveis intrafirma, como por exemplo a cultura e o perfil inovador dos seus agentes, questões macro também impactam a Petrobras, como as Políticas monetária, cambial e tributária do País, além de questões de Regulação e de paradigma técnicocientífico.

Deste modo, fundamental para a Petrobras é a dimensão de ganhos relacionais que a Gestão do Conhecimento e o seu Sistema de Conhecimento e Inovação propiciam via 
vasta parceria que o CENPES articula com universidades e instituições de pesquisa. Significativa questão diz respeito a como esta Rede é dinamizada de forma que conquiste resultados e desenvolva ativos que a Empresa de forma individual não teria condições de produzir - por razões de ordem interna, externa e sistêmica. Indaga-se como esta mesma Rede de capacitações e capacidades, ao integrar ativos fixos e/ou intangíveis, permite e permitirá à Petrobras ampliar a sua vantagem competitiva, por exemplo, em águas ultraprofundas do Pré-sal do Brasil. Neste processo, a colaboração e cooperação para o desenvolvimento de conhecimentos estratégicos mediante a integração da Estatal com a sua rede de fornecedores e com outros grupos de interesse também é algo que precisa ser pesquisado no âmbito da Gestão do Conhecimento.

Em vista disto, o fato do CENPES possuir 1.862 empregados, com 1.384 voltados à Pesquisa e Desenvolvimento, com outros 309 na Engenharia Básica, aponta o quanto de recurso de conhecimento explícito a Petrobras pode possui apenas nesta Unidade. Isto assume alto refinamento quando se sabe que $32 \%$ dos pesquisadores têm a titulação de Mestrado e $17 \%$ de Doutorado. Neste cenário, importante é se conhecer quais encontros formais e informais agenciam o conhecimento tácito existente e como o processo de conversão do conhecimento é arquitetado e objetivado de forma interna e externa e mediante quais recursos de tecnologia. Deste modo será possível compreender e apreender, por exemplo, a dinâmica que permitiu a inovação vinculada ao método de redirecionamento de injeção de gás em coluna de produção em poços com gás lift. Para tanto, investigar as Dimensões de busca, de seleção, de implementação e em especial de captura de valor, ou seja, adoção sustentável e difusão, que inclui tanto o aprendizado quanto o aperfeiçoamento profissional contínuos, apresentam-se como fundamental para que a Petrobras possa aperfeiçoar o seu Sistema de Conhecimento e Inovação.

Em vista disto, mediante Reflexão desenvolvida no Artigo e tendo em vista a atual Crise do Petróleo, afirma-se que inovações organizacionais relativas a Novas Técnicas de Gestão e, por conseguinte, à Gestão do Conhecimento, são de crucial estratégia para o Setor de Óleo \& Gás do Brasil e para a própria Petrobras. Assim, a Empresa poderá enfrentar, com melhor efetividade, os desafios de competitividade global no contexto de considerável queda de preços do barril do petróleo. Isto, no cenário de alta volatilidade e de intensa complexidade e custo de projetos e operações da cadeia produtiva.

Deste modo, significativo é aprofundar a pesquisa, o conhecimento, a análise e a avaliação da Inovação Organizacional implementada na Exploração e Produção Offshore - em particular no cenário de intrafirma e da Gestão do Conhecimento sem se descuidar de variáveis pertencentes a sistemas de inovação e a inovações setoriais. Com isto, como potencial desdobramento desta Reflexão, competências organizacionais e profissionais, identificadas, mapeadas e interpretadas, têm a força de nortear (micro) políticas tanto de inovação quanto de treinamento, desenvolvimento e educação em organizações vinculadas às Indústrias de petróleo, gás natural e biocombustíveis.

Por fim, a conexão do que foi trabalhado ao longo deste Artigo com a Sustentabilidade Econômica apresenta-se clara e objetiva, em particular quanto ao setor de fabricação de coque, de produtos derivados do petróleo e de biocombustíveis e acerca do setor de coque e biocombustíveis (álcool e outros), incluindo o setor de refino do petróleo - em especial quanto circunscritos à atividade offshore do Pré-sal do Brasil.

\section{Referências Bibliográficas}


ALMEIDA, Edmar Fagundes de. Custos e competitividade da exploração e produção no Brasil. Rio de Janeiro: IBP - Instituto Brasileiro de Petróleo, Gás e Biocombustíveis. Palestra ministrada no Ciclo de Debates sobre Petróleo e Economia - Custos e Competitividade do Setor de Petróleo no Brasil em 20 maio 2016.

ALMEIDA, Edmar Fagundes de. Shale gas: perspectivas da exploração fora da América do Norte. Boletim Infopetro. Rio de Janeiro: Universidade Federal do Rio de Janeiro. Instituto de Economia - setembro/outubro de 2014 - ano 14 - n. 4 - p. 26-32 ISSN 1679-1355 Disponível em https://infopetro.files.wordpress.com/2014/10/infopetro09102014.pdf Acesso 9 junho 2016.

BRASIL. Ministério do Planejamento, Orçamento e Gestão. Instituto Brasileiro de Geografia e Estatística - IBGE. Diretoria de Pesquisas. Coordenação de Indústria. Pesquisa de Inovação Tecnológica 2008. Rio de Janeiro: IBGE, 2010. 164p. Disponível em

http://www.pintec.ibge.gov.br/index.php?option=com_content\&view=article\&id=45\&It emid=12 Acesso 7 junho 2016.

BRASIL. Ministério do Planejamento, Orçamento e Gestão. Instituto Brasileiro de Geografia e Estatística - IBGE. Diretoria de Pesquisas. Coordenação de Indústria. Pesquisa Inovação 2011. Rio de Janeiro: IBGE, 2013. 227p. Disponível em http://www.pintec.ibge.gov.br/index.php?option=com_content\&view=article\&id=45\&It emid=12 Acesso 7 junho 2016.

CARVALHO, Fábio Câmara Araújo de (Org.). Gestão do Conhecimento. São Paulo: Pearson. 2012. 298p.

COLOMER, Marcelo. A relação entre o mercado de gás natural, o mercado de LGN e o mercado de petróleo nos Estados Unidos. Boletim Infopetro. Rio de Janeiro: Universidade Federal do Rio de Janeiro. Instituto de Economia - novembro/dezembro de 2014 - ano 14 - n. 5 - p. 27-32 ISSN 1679-1355 Disponível em https://infopetro.files.wordpress.com/2014/12/infopetro11122014.pdf Acesso 9 junho 2016.

COLOMER, Marcelo. $\underline{\mathrm{O} \text { setor elétrico e as indefinições da política de gás natural no }}$ Brasil. Boletim Infopetro. Rio de Janeiro: Universidade Federal do Rio de Janeiro. Instituto de Economia - maio/junho de 2014 - ano 14 - n. 2 - p. 39-44 ISSN 1679-1355 Disponível em https://infopetro.files.wordpress.com/2014/07/infopetro05062014.pdf Acesso 9 junho 2016.

IBP - INSTITUTO BRASILEIRO DE PETRÓLEO, GÁS E BIOCOMBUSTÍVEIS. Agenda prioritária da indústria de petróleo, gás e biocombustíveis 2014-2015. Rio de Janeiro: IBP, [201-]. 59p. Disponível em http://www.ibp.org.br/publicacoes/ Acesso 14 junho 2016.

LOSEKANN, Luciano; ALMEIDA, Edmar Fagundes de. A transformação do panorama global do petróleo e do gás e os impactos sobre o Brasil. Boletim Infopetro. Rio de Janeiro: Universidade Federal do Rio de Janeiro. Instituto de Economia novembro/dezembro de 2014 - ano 14 - n. 5 - p. 21-26 ISSN 1679-1355 Disponível em 
https://infopetro.files.wordpress.com/2014/12/infopetro11122014.pdf Acesso 9 junho 2016.

ORGANIZAÇÃO PARA COOPERAÇÃO E DESENVOLVIMENTO ECONÔMICO. GABINETE ESTATÍSTICO DAS COMUNIDADES EUROPEIAS. Manual de Oslo: diretrizes para coleta e interpretação de dados sobre inovação. 3. ed. OCDE, 1997. Tradução de Financiadora de Estudos e Projetos - FINEP. 184p. Disponível em http://www.finep.gov.br/images/apoio-e-financiamento/manualoslo.pdf Acesso 19 junho 2016.

PELLEGRIN, Ivan de; ANTUNES JÚNIOR, José Antonio Valle. Inovação: uma discussão conceitual a partir da perspectiva da cadeia de valor. In: PROENÇA, Adriano; LACERDA, Daniel Pacheco; ANTUNES JÚNIOR, José Antonio Valle; TÁVORA JUNIOR, José Lamartine; SALERNO, Mario Sergio (Org.). Gestão da inovação e competitividade no Brasil: da teoria para a prática. Porto Alegre: Bookman, 2015. 243p.

PETROBRAS. Fatos e dados: somos referência em gestão do conhecimento, aponta Ipea. Disponível em http://www.petrobras.com.br/fatos-e-dados/somos-referencia-emgestao-do-conhecimento-aponta-ipea.htm Acesso 24 junho 2016.

PETROBRAS. Relatório de gestão 2014. Brasília: Ministério de Minas e Energia, 2015. 440p. Disponível em http://sites.petrobras.com.br/downloads/aboutus/profile/transparency/doc/AUDITORIA/relatorio-gestao-petrobras-2014.pdf Acesso 16 junho 2016.

PRODANOV, Cleber Cristiano; FREITAS, Ernani Cesar de. Metodologia do trabalho científico: métodos e técnicas da pesquisa e do trabalho acadêmico. 2. ed. Novo Hamburgo (RS): Universidade Feevale, 2013. 277p. Disponível em http://www.feevale.br/Comum/midias/8807f05a-14d0-4d5b-b1ad-1538f3aef538/Ebook\%20Metodologia\%20do\%20Trabalho\%20Cientifico.pdf Acesso 26 junho 2016.

RODRIGUEZ Y RODRIGUEZ, Martius Vicente (Org.). Gestão do conhecimento e inovação nas empresas. Rio de Janeiro: Qualitymark, 2013. 407p.

SERRA, Fernando Ribeiro; FERREIRA, Manuel Portugal; TORRES, Alexandre Pavan; TORRES, Maria Candida. Gestão estratégica: conceitos e casos. São Paulo: Atlas, 2014. 388p.

SICSÚ, Abraham Benzaquen. Desenvolvimento e padrões de financiamento da inovação no Brasil: mudanças necessárias. In: PROENÇA, Adriano; LACERDA, Daniel Pacheco; ANTUNES JÚNIOR, José Antonio Valle; TÁVORA JUNIOR, José Lamartine; SALERNO, Mario Sergio (Org.). Gestão da inovação e competitividade no Brasil: da teoria para a prática. Porto Alegre: Bookman, 2015. 243p.

SCHUMPETER, J. A. Capitalismo, socialismo e democracia. Rio de Janeiro: Zahar, 1984. In: SICSÚ, Abraham Benzaquen. Desenvolvimento e padrões de financiamento da inovação no Brasil: mudanças necessárias. In: PROENÇA, Adriano; LACERDA, Daniel Pacheco; ANTUNES JÚNIOR, José Antonio Valle; TÁVORA JUNIOR, José Lamartine; SALERNO, Mario Sergio (Org.). Gestão da inovação e competitividade no Brasil: da teoria para a prática. Porto Alegre: Bookman, 2015. 243p. 
SCHUMPETER, J. A. Capitalismo, socialismo e democracia. São Paulo: Ed. Abril, 1982. In: SICSÚ, Abraham Benzaquen. Teoria do desenvolvimento econômico. In: PROENÇA, Adriano; LACERDA, Daniel Pacheco; ANTUNES JÚNIOR, José Antonio Valle; TÁVORA JUNIOR, José Lamartine; SALERNO, Mario Sergio (Org.). Gestão da inovação e competitividade no Brasil: da teoria para a prática. Porto Alegre: Bookman, 2015. 243p.

TIDD, Joe; BESSANT, John. Gestão da inovação. 5. ed. Porto Alegre: Bookman, 2015. 633p.

TIGRE, Paulo Bastos. Gestão da inovação: a economia da tecnologia no Brasil. 2. ed. Rio de Janeiro: Elsevier, 2014. 275p. 